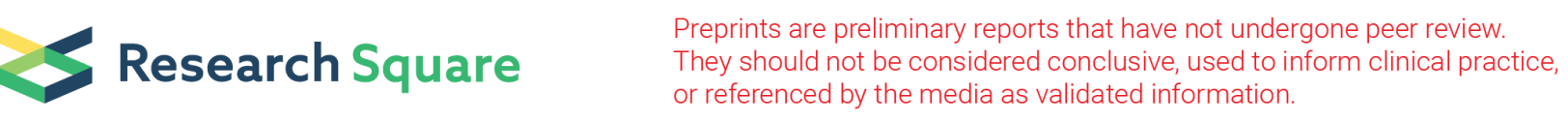

\title{
MicroRNA-411 represents an innovative bio-marker in breast cancer detection
}

\section{Shuangqing Cao ( $D$ opxdfh@yeah.net)}

Harrison International Peace Hospital https://orcid.org/0000-0001-6167-7515

\section{Lei Zheng}

Harrison International Peace Hospital

Primary research

Keywords: MicroRNA-411, Diagnosis, Breast cancer

Posted Date: August 7th, 2020

DOI: https://doi.org/10.21203/rs.3.rs-54155/v1

License: (a) (i) This work is licensed under a Creative Commons Attribution 4.0 International License. Read Full License 


\section{Abstract}

Background: MicroRNA-411 (MiR-411) has been reported to play an important role in tumorigenesis. This study was aimed to investigate the diagnostic performance of serum miR-411 in breast cancer.

Methods: The serum level of miR-411 was determined in breast cancer patients using quantitative realtime PCR (qRT-PCR). Chi-square was applied to evaluate the association between miR-411 expression and clinical characteristics. The diagnostic value of serum miR-411 for breast cancer was estimated using receiver operator characteristic (ROC) analysis.

Results: Serum miR-411 in patients with breast cancer was markedly decreased compared with healthy controls $(P<0.001)$. The level of miR-411 was correlated with clinical stage $(P=0.019)$, histological grade ( $P=0.014)$, and lymph node metastasis $(P=0.036)$. ROC curve showed that serum level of miR-411 could discriminate between breast cancer patients and healthy controls, with the AUC of 0.796 , combing with the sensitivity of $82.1 \%$ and the specificity of $83.2 \%$. The cut-off value of miR-411 for breast cancer diagnosis was 1.245 .

Conclusions: MiR-411 plays inhibitory roles in aggressive progression of breast cancer. Serum miR-411 may be a potential non-invasive biomarker for breast cancer diagnosis.

\section{Background}

Breast cancer is one of the most common cancers among women, with severe mortality [1]. The mainly cause of breast cancer death is tumor metastasis [2]. Despite of great progress made in treatments, numbers of breast cancer patients die from the metastatic disease [3]. The therapeutic effects are significantly associated with tumor stage at diagnosis [4]. Early detection remains a major challenge for breast cancer [5]. Biomarkers detection provides an effective approach for early diagnosis of breast cancer. The commonly used biomarkers for breast cancer diagnosis include CEA (carcinoembryonic antigen), CA153 (carbohydrate antigen 153), HER-2/Neu, estrogen receptor (ER), progesterone receptor (PR), epidermal growth factor receptor (EGFR), and vascular endothelial growth factor receptor (VEGFR) [6]. Unfortunately, the low specificity and sensitivity limit their clinical application in breast cancer screening [7-9]. As a consequence, new biomarkers are urgently needed in early detection and screening of breast cancer.

MicroRNAs (miRNAs) are a novel class of small non-coding RNAs that play regulatory roles in gene expression at the post-transcriptional level $[10,11]$. MiRNAs take part in regulation of various important cellular processes, such as differentiation, migration, and apoptosis [12]. Abnormal expression of miRNAs may contribute to pathological mechanisms of human disease, like cancer [13]. The expression profiles of miRNAs are stable in body fluids and archived tissue samples which can be detected by non-invasive methods, suggesting that detection of miRNAs may provide a promising way for cancer diagnosis [1416]. MicroRNA-411 (MiR-411) is a common member of miRNA family, and its dysregulation has been reported to be associated with several types of cancer. For examples, Xia et al. reported that miR-411 
served as an oncogene in hepatocellular carcinoma by promoting cell proliferation of the cancer cells [17]. However, until now, the serum level of $m i R-411$ and its diagnostic performance in breast cancer remained unidentified.

In the current study, we sought to investigate diagnostic performance of serum miR-411 in breast cancer. The serum levels of miR-411 in breast cancer patients were detected, as well as its association with clinical characteristics. In addition, receiver operating characteristic (ROC) analysis was performed to determine the diagnostic value of miR-411 in breast cancer.

\section{Methods}

\section{Patients and serum samples}

The present study was approved by the the Ethical Committee of the hospital and all participants provided written informed consents in advance. 107 patients who were pathologically diagnosed with breast cancer at Harrison International Peace Hospital were enrolled in the study. None of the patients had received surgery, chemotherapy, or radiotherapy before blood collection. The control blood samples were collected from 95 age-matched healthy volunteers who were without malignancy history and inflammatory diseases. Clinicopathological features of patients were summarized in Table 1. 
Table 1

Association of serum miR-411 level with clinicopathological factors

\begin{tabular}{|c|c|c|c|c|c|}
\hline \multirow[t]{2}{*}{ Factors } & \multirow{2}{*}{$\begin{array}{l}\text { NO. of cases } \\
(n=107)\end{array}$} & \multicolumn{2}{|c|}{ miR-411 expression } & \multirow{2}{*}{$x^{2}$} & \multirow[t]{2}{*}{$P$ values } \\
\hline & & $\operatorname{Low}(n=59)$ & High $(n=48)$ & & \\
\hline \multicolumn{6}{|c|}{ Age (years) } \\
\hline$<55$ & 61 & 31 & 30 & 1.071 & 0.301 \\
\hline$\geq 55$ & 46 & 28 & 18 & & \\
\hline \multicolumn{6}{|c|}{ Clinical stage } \\
\hline$\rrbracket-\bigotimes$ & 85 & 42 & 43 & 5.484 & 0.019 \\
\hline ૧ & 22 & 17 & 5 & & \\
\hline \multicolumn{6}{|c|}{ Histological grade } \\
\hline$\triangle-\bigotimes$ & 69 & 32 & 37 & 6.032 & 0.014 \\
\hline ૫ & 38 & 27 & 11 & & \\
\hline \multicolumn{6}{|c|}{ Tumor diameter (cm) } \\
\hline$<2$ & 51 & 26 & 25 & 0.682 & 0.409 \\
\hline$\geq 2$ & 56 & 33 & 23 & & \\
\hline \multicolumn{6}{|c|}{ Lymph node metastasis } \\
\hline Negative & 76 & 37 & 39 & 4.420 & 0.036 \\
\hline Positive & 31 & 22 & 9 & & \\
\hline \multicolumn{6}{|l|}{ ER status } \\
\hline Negative & 67 & 34 & 33 & 1.399 & 0.237 \\
\hline Positive & 40 & 25 & 15 & & \\
\hline \multicolumn{6}{|l|}{ PR status } \\
\hline Negative & 68 & 35 & 33 & 1.016 & 0.314 \\
\hline Positive & 39 & 24 & 15 & & \\
\hline \multicolumn{6}{|c|}{ HER-2/neu status } \\
\hline Negative & 75 & 40 & 35 & 0.331 & 0.565 \\
\hline Positive & 32 & 19 & 13 & & \\
\hline
\end{tabular}


$5 \mathrm{ml}$ whole blood was collected from each participant in a serum separator tube containing EDTA. Samples were left to clot at room temperature for $30 \mathrm{~min}$ and then were centrifuged at 4,000 rpm for 10 min at $4^{\circ} \mathrm{C}$. Serum specimens were stored at $-80^{\circ} \mathrm{C}$ until further use.

\section{RNA extraction and quantitative real-time ploymerase chain reaction (qRT-PCR)}

Total RNA was extracted from serum using the standard TRIZOL LS (Invitrogen, CA, USA) method according to the manufacturer's protocol. Total RNA concentration and integrity were determined with an ultraviolet specrophotometer (Beckman, CA, USA) and a digital gel image analysis system (Bio-Rad, CA, USA).

Total RNA samples were reversely transcribed (RT) to cDNAs using primers specific to miR-411 target. Specific cDNAs were then amplified by real-time quantitative RT-PCR using SYBR Premix Ex Taq (Takara, China) to investigate the relative expression of miR-411. The relative expression of miRNA was normalized to $U 6$ and calculated with the $2^{-\Delta \Delta \mathrm{Ct}}$ method [18].

\section{Statistical analysis}

All statistical analyses were carried out with SPSS 18.0 software and GraphPad prism 5. Data were presented as mean \pm SD. MiR-411 expression levels were compared using Students's $t$ test. The relationships between miR-411 expression and clinicopathological factors were analyzed using chisquare test. Receiver operating characteristics (ROC) curves were established to evaluate the diagnostic value of serum miR-411 in breast cancer. $P<0.05$ was considered statistically significant.

\section{Results}

\section{The expression level of serum miR-411 from breast cancer patients and healthy controls}

QRT-PCR assay was carried out to measure the serum level of miR-411 in 107 patients with breast cancer and 95 healthy controls. As shown in Fig. 1, the expression of serum miR-411 were significantly lower in breast cancer than that in healthy controls $(P<0.001)$.

\section{The association between serum miR-411 expression and clinicopathological characteristics}

The patients were divided into high expression group $(n=48)$ and low expression group $(n=59)$, according to their average expression level of miR-411. To further determine the clinical significance of serum miR-411 expression, chi-square test was performed. Results showed that miR-411 was obviously associated with clinical stage $(P=0.019)$, histoltogical stage $(P=0.014)$ and lymph node status $(P=$ 0.036). No significantly differences were found between miR-411 and other clinicopathological features, 
including age, tumor diameter, lymph node status, ER status, PR status and HER-2/neu status (all $P>$ 0.05) (Table 1). It indicated that miR-411 was implicated with the development and metastasis of breast cancer.

\section{The diagnostic value of miR-411 in breast cancer}

ROC curves which were built based on serum levels of miR-411 in breast cancer patients and healthy individuals were used to evaluate the diagnostic value of miR-411 for breast cancer. The curve showed that serum miR-411 could distinguish breast cancer patients from healthy individuals at the optimal cutoff value of 1.245 , with the an area under the curve (AUC) of 0.796 , combing with the sensitivity of $82.1 \%$ and the specificity of $83.2 \%$ (Fig. 2).

\section{Discussion}

Breast cancer is a severe threat to health among women worldwide, due to its high incidence rates and low overall survival [19]. Tumor metastasis may be responsible for the dismal clinical outcomes of breast cancer [3]. Unfortunately, the etiology of breast cancer remains unclear, and it is unable to determinate the key factor for tumor progression [20]. Early diagnosis is a pivotal approach to improve outcomes of breast cancer patients. Until now, the commonly used biomarkers for breast cancer diagnosis, such as CEA, CA153, HER-2/Neu, ER, PR, and EGFR, show limited diagnostic effectiveness [21]. Therefore, it is necessary to identify new diagnostic biomarkers for breast cancer patients to improve prognosis.

Growing evidences have suggested that miRNAs may provide an effective tool for cancer diagnosis, due to its stable expression profiles in body fluids and tissues specimens, as well as its significantly association with tumor progression [22]. In breast cancer, a variety of dysregulated miRNAs were observed, suggesting their important functions in tumor development and progression. MiR-4262 was proved to be a tumor oncogene in breast cancer that its over-expression might contribute to proliferation and invasion of the cancer cells [23]. MiR-421 was down-regulated in breast cancer tissues specimens and cell lines, and its expression patterns showed negative link with metastasis, tumor stage and recurrence. MiR-421 might be a tumor suppressor in breast cancer [24]. Given their functional roles in progression of breast cancer, miRNAs were considered as promising biomarkers for the disease. In the present study, we investigated the diagnostic significance of $m i R-411$ in breast cancer.

In this study, we found miR-411 expression was decreased in serum samples collected from breast cancer patients compared with healthy controls. Moreover, the down-regulated serum miR-411 levels were tightly correlated with advanced clinical stage, high histological grade, and positive lymph node metastasis. It suggested that miR-411, as a tumor suppressor, was involved in the progression of breast cancer. The conclusion was consistent with the previous investigations. It was reported that the expression of miR-411 was significantly down-regulated in breast cancer patients, and recovery its expression might suppress growth, migration, and invasion of the cancer cells [25, 26]. However, the molecular mechanisms for the anti-tumor action of miR-411 in breast cancer remained poorly known. Further researches were still needed. 
Breast cancer diagnosis is a challenging research job. The cancer is characterized by heterogeneous, with diverse genetic alterations [27]. In the previous studies, various molecular biomarkers were confirmed for breast cancer. For instances, Zhang et al. reported that plasma long non-coding $H 19$ levels were significantly different between breast cancer patients and healthy individuals that might be a potential diagnostic biomarker for the disease [28]. The study carried out by Chen et al. demonstrated that serum levels of DAND 5 were positively correlated with aggressive clinical characteristics and low survival rate of breast cancer patients, suggesting its predictive potential in the cancer [3]. Identification of genetic alterations might provide an effective approach for early diagnosis and prognosis evaluation of breast cancer. In this study, ROC curve analysis was performed to investigate the diagnostic performance of miR-411 in breast cancer patients. The results revealed that serum miR-411 expression could differentiate breast cancer patients from healthy controls with satisfactory sensitivity and specificity. Despite of the various identified molecular biomarkers for breast cancer, few of them were applied in clinic. Therefore, well-designed study with large sample size was still needed to investigate the application value of serum miR-411 for breast cancer diagnosis.

\section{Conclusions}

In conclusion, serum miR-411 levels in patients with breast cancer is down-regulated, and its decreased expression correlates with malignant tumor progression. Serum miR-411 may be a potential biomarker for early detection of breast cancer.

\section{Abbreviations}

\section{MicroRNA-411 (MiR-411)}

quantitative real-time PCR (qRT-PCR)

receiver operator characteristic (ROC)

estrogen receptor (ER)

progesterone receptor (PR)

epidermal growth factor receptor (EGFR)

vascular endothelial growth factor receptor (VEGFR)

MicroRNAs (miRNAs)

quantitative real-time ploymerase chain reaction ( $q R T-P C R$ )

area under the curve (AUC) 


\section{Declarations}

\section{Ethics approval and consent to participate}

This study was supported by the Ethics Committee of Harrison International Peace Hospital and also has been carried out in accordance with the World Medical Association Declaration of Helsinki.

The subjects had been informed the objective. Certainly, written consents were signed by every subject in this study.

\section{Consent for publication}

We obtaining permission from participants to publish their data.

\section{Availability of data and materials}

The datasets used and/or analysed during the current study are available from the corresponding author on reasonable request.

\section{Competing interests}

The authors declare that they have no competing interests.

\section{Funding}

Not applicable.

\section{Authors' contributions}

S.C., L.Z. design of the work; S.C., L.Z. the acquisition, analysis, S.C., L.Z. interpretation of data; S.C., L.Z. the creation of new software used in the work; S.C., L.Z. have drafted the work or substantively revised it. All authors read and approved the final manuscript.

\section{Acknowledgements}

Not applicable.

\section{References}


1. Jemal A, Bray F, Center MM, Ferlay J, Ward E, Forman D: Global cancer statistics. CA: a cancer journal for clinicians 2011, 61(2):69-90.

2. Johnson CJ, Graff R, Moran P, Cariou C, Bordeaux S: Breast cancer stage, surgery, and survival statistics for Idaho's National Breast and Cervical Cancer Early Detection Program population, 20042012. Preventing chronic disease 2015, 12:E36.

3. Chi Y, Yao L, Hu X, Huang S, Huang N, Li S, Shao Z, Wu J: The BMP inhibitor DAND5 in serum predicts poor survival in breast cancer. Oncotarget 2016, 7(12):14951-14962.

4. Siegel R, DeSantis C, Virgo K, Stein K, Mariotto A, Smith T, Cooper D, Gansler T, Lerro C, Fedewa S et al: Cancer treatment and survivorship statistics, 2012. CA: a cancer journal for clinicians 2012, 62(4):220-241.

5. Maxmen A: The hard facts. Nature 2012, 485(7400):S50-51.

6. Bi Y, Tian M, Le J, Wang L, Liu X, Qu J, Hao M: Study on the expression of PAK4 and P54 protein in breast cancer. World journal of surgical oncology 2016, 14(1):160.

7. Harris L, Fritsche H, Mennel R, Norton L, Ravdin P, Taube S, Somerfield MR, Hayes DF, Bast RC, Jr.: American Society of Clinical Oncology 2007 update of recommendations for the use of tumor markers in breast cancer. Journal of clinical oncology : official journal of the American Society of Clinical Oncology 2007, 25(33):5287-5312.

8. Duffy MJ, Evoy D, McDermott EW: CA 15-3: uses and limitation as a biomarker for breast cancer. Clinica chimica acta; international journal of clinical chemistry 2010, 411(23-24):1869-1874.

9. Patani N, Martin LA, Dowsett M: Biomarkers for the clinical management of breast cancer: international perspective. International journal of cancer Journal international du cancer 2013, 133(1):1-13.

10. Ha M, Kim VN: Regulation of microRNA biogenesis. Nature reviews Molecular cell biology 2014, 15(8):509-524.

11. Ameres SL, Zamore PD: Diversifying microRNA sequence and function. Nature reviews Molecular cell biology 2013, 14(8):475-488.

12. Clark EA, Kalomoiris S, Nolta JA, Fierro FA: Concise review: MicroRNA function in multipotent mesenchymal stromal cells. Stem Cells 2014, 32(5):1074-1082.

13. Shen J, Stass SA, Jiang F: MicroRNAs as potential biomarkers in human solid tumors. Cancer letters 2013, 329(2):125-136.

14. Corcoran C, Friel AM, Duffy MJ, Crown J, O'Driscoll L: Intracellular and extracellular microRNAs in breast cancer. Clinical chemistry 2011, 57(1):18-32.

15. Godfrey AC, Xu Z, Weinberg CR, Getts RC, Wade PA, DeRoo LA, Sandler DP, Taylor JA: Serum microRNA expression as an early marker for breast cancer risk in prospectively collected samples from the Sister Study cohort. Breast cancer research : BCR 2013, 15(3):R42.

16. Ng EK, Li R, Shin VY, Jin HC, Leung CP, Ma ES, Pang R, Chua D, Chu KM, Law WL et al: Circulating microRNAs as specific biomarkers for breast cancer detection. PloS one 2013, 8(1):e53141. 
17. Xia K, Zhang Y, Cao S, Wu Y, Guo W, Yuan W, Zhang S: miR-411 regulated ITCH expression and promoted cell proliferation in human hepatocellular carcinoma cells. Biomedicine \& pharmacotherapy $=$ Biomedecine $\&$ pharmacotherapie 2015, 70:158-163.

18. Schmittgen TD, Livak KJ: Analyzing real-time PCR data by the comparative $\mathrm{C}(\mathrm{T})$ method. Nature protocols 2008, 3(6):1101-1108.

19. Hu JY, Yi W, Zhang MY, Xu R, Zeng LS, Long XR, Zhou XM, Zheng XS, Kang Y, Wang HY: MicroRNA711 is a prognostic factor for poor overall survival and has an oncogenic role in breast cancer. Oncology letters 2016, 11(3):2155-2163.

20. Zhou CX, Wang CL, Yu AL, Wang QY, Zhan MN, Tang J, Gong XF, Yin QQ, He M, He JR et al: MiR-630 suppresses breast cancer progression by targeting metadherin. Oncotarget 2016, 7(2):1288-1299.

21. Zhang L, Song X, Wang X, Xie Y, Wang Z, Xu Y, You X, Liang Z, Cao H: Circulating DNA of HOTAIR in serum is a novel biomarker for breast cancer. Breast cancer research and treatment 2015, 152(1):199-208.

22. Mulrane L, Klinger R, McGee SF, Gallagher WM, O'Connor DP: microRNAs: a new class of breast cancer biomarkers. Expert review of molecular diagnostics 2014, 14(3):347-363.

23. Wang K, Ren Y, Liu Y, Zhang J, He JJ: MiR-4262 promotes proliferation and invasion of human breast cancer cells through directly targeting KLF6 and KLF15. Oncology research 2016.

24. Pan Y, Jiao G, Wang C, Yang J, Yang W: MicroRNA-421 inhibits breast cancer metastasis by targeting metastasis associated 1. Biomedicine \& pharmacotherapy = Biomedecine \& pharmacotherapie 2016, 83:1398-1406.

25. van Schooneveld E, Wouters MC, Van der Auwera I, Peeters DJ, Wildiers H, Van Dam PA, Vergote I, Vermeulen PB, Dirix LY, Van Laere SJ: Expression profiling of cancerous and normal breast tissues identifies microRNAs that are differentially expressed in serum from patients with (metastatic) breast cancer and healthy volunteers. Breast cancer research : BCR 2012, 14(1):R34.

26. Guo L, Yuan J, Xie N, Wu H, Chen W, Song S, Wang X: miRNA-411 acts as a potential tumor suppressor miRNA via the downregulation of specificity protein 1 in breast cancer. Molecular medicine reports 2016, 14(4):2975-2982.

27. Liu H, Li J, Koirala P, Ding X, Chen B, Wang Y, Wang Z, Wang C, Zhang X, Mo YY: Long non-coding RNAs as prognostic markers in human breast cancer. Oncotarget 2016, 7(15):20584-20596.

28. Zhang K, Luo Z, Zhang Y, Zhang L, Wu L, Liu L, Yang J, Song X, Liu J: Circulating IncRNA H19 in plasma as a novel biomarker for breast cancer. Cancer biomarkers : section A of Disease markers 2016, 17(2):187-194.

\section{Figures}




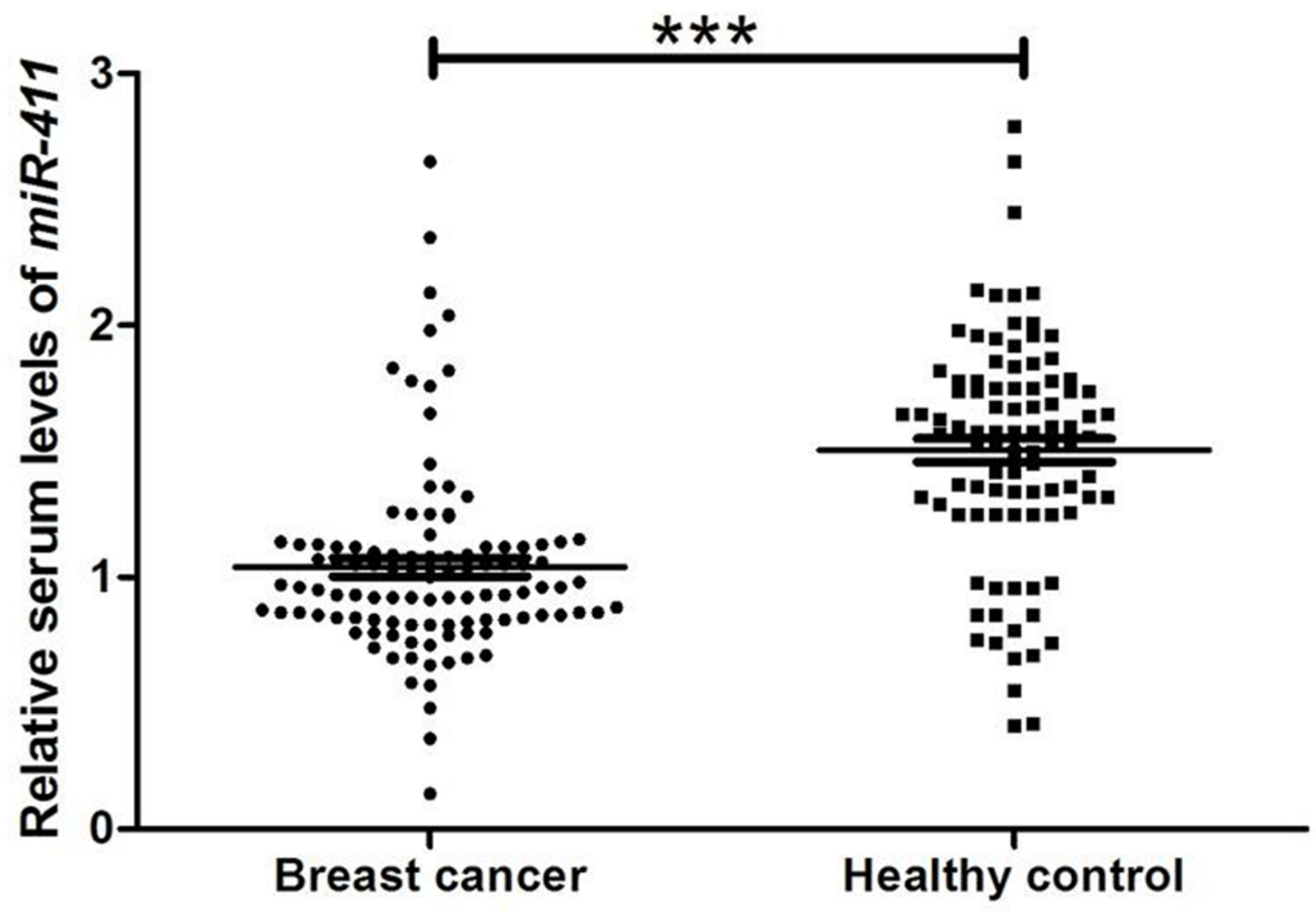

Figure 1

Serum miR-411 levels in 107 breast cancer and 95 healthy controls. Serum expression level of miR-411 in breast cancer were strongly down-regulated compared with healthy controls. ***: suggested $P<0.001$. 


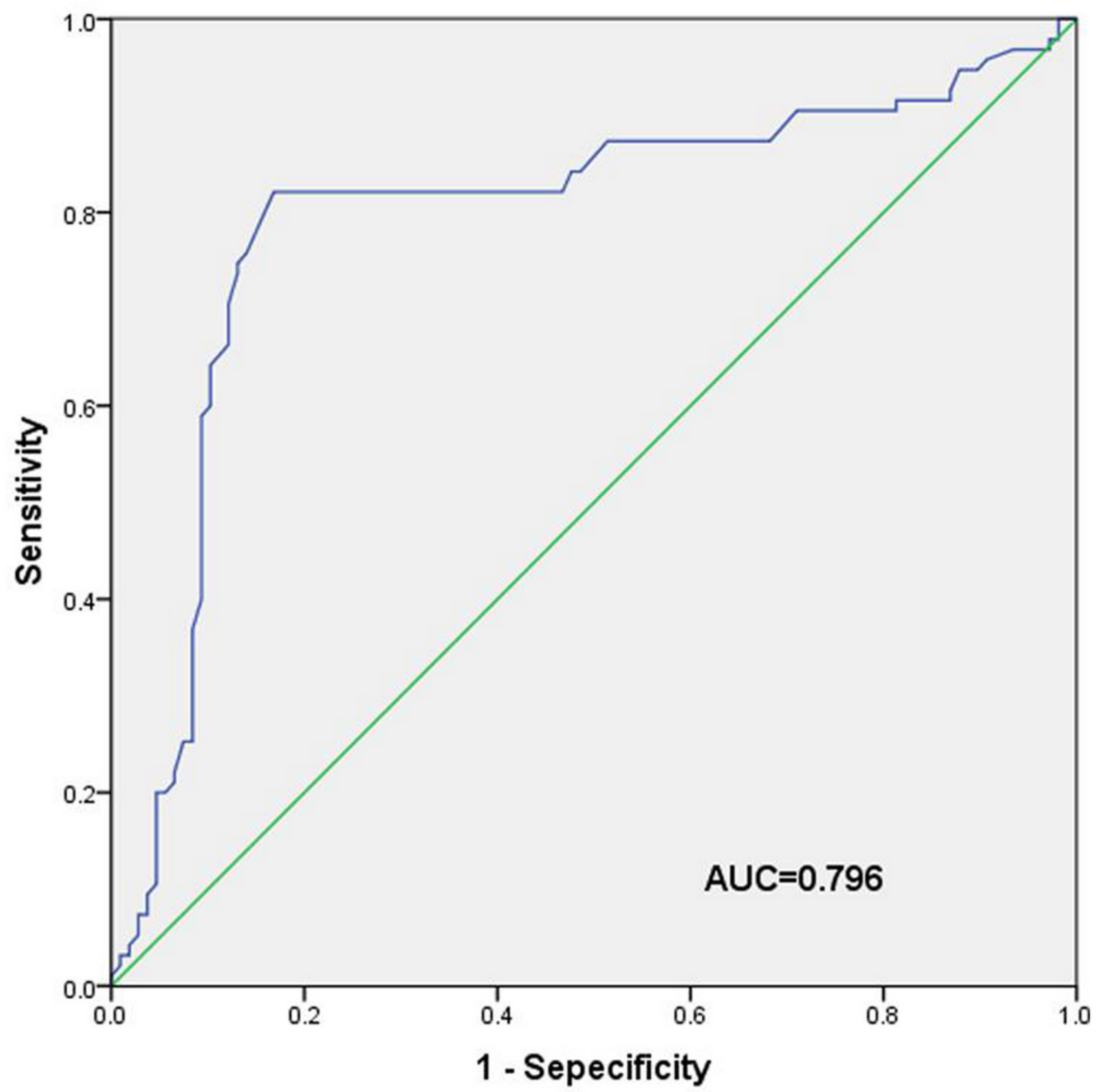

Figure 2

Receiver operating characteristics (ROC) curve constructed based on serum levels of miR-411 in breast cancer patients and healthy controls. The AUC value of the curve was 0.796 , suggesting that miR-411 could discriminate between breast cancer patients and healthy individuals. The cut-off value of miR-411 for breast cancer diagnosis was 1.245 , with the sensitivity of $82.1 \%$ and the specificity of $83.2 \%$. 